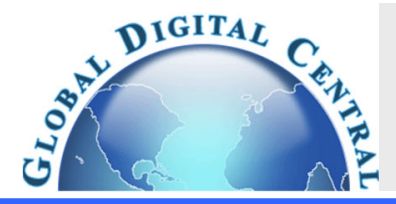

Frontiers in Heat and Mass Transfer

Available at www.ThermalFluidsCentral.org

Frontiers
in Heatand
Mass Transfer

\title{
NUMERICAL THERMAL STUDY OF HEAT TRANSFER ENHANCEMENT IN LAMINAR-TURBULENT TRANSITION FLOW THROUGH ABSORBER PIPE OF PARABOLIC SOLAR TROUGH COLLECTOR SYSTEM
}

\author{
Marwa M. Ibrahim $^{\mathrm{a},{ }^{*} \text {, Mohamed Mahran Kasem }}{ }^{\text {b,c }}$ \\ ${ }^{a}$ Mechanical Engineering Department, National Research Centre (NRC), Dokki, Cairo, 12622, Egypt \\ ${ }^{b}$ Aerospace Engineering Department, Cairo University, Giza, 12613, Egypt \\ ${ }^{c}$ Nile University, Giza,16453, Egypt
}

\begin{abstract}
Currently electricity generation technologies by thermal energy conversions become strong demand. The objective of this paper is to present a novel thermal study of absorber/receiver circular pipe of parabolic trough solar collector system for laminar and turbulent (k- $\varepsilon$ model) fluids flow as well as two-dimensional numerical simulation is performed using CFD ANSYS FLUENT software. Significant improvements in heat transfer and velocity were discovered; the pattern of temperature distribution over the pipe absorber was displayed, and velocity vectors, pressure contours, and temperature contours were studied. The impact of increasing the heat flux towards the pipe wall is discussed. Heat transfer coefficient and Nusselt number increases with increasing of Reynolds number while drag and skin friction coefficients decrease when Reynolds number increases. The thermal performance factor of PTC is estimated, and it is found $74 \%$ in laminar flow condition. The model is validated by comparing its results with analytical model results and the validation approves the accuracy of the CFD analysis. In the future, it will be useful for solar thermal parabolic trough concentrators to study different working fluids for heat transfer.
\end{abstract}

Keywords: Concentrated solar power; Thermal study; Heat transfer; Reynolds number and Laminar \& $k$ - turbulent model

\section{INTRODUCTION}

Of all the renewable energy sources, solar energy has the greatest potential; it is vital in order to achieve the sustainability and reduced the utilization of conventional energy sources. For all practical purposes, solar energy is readily available, well distributed, and inexhaustible and, when converted and used, has no polluting effects on the earth. Solar energy divided into two categories: solar electrical energy photovoltaic panels and solar thermal energy. Concentrated Solar Power (CSP) system converts solar energy to heat; it uses mirrors to focus solar light in smaller area, transmitting this energy through absorber pipe to the working fluid that transforms the electricity generation by turbine.

There are different types of CSP system; the Parabolic Trough Collector (PTC) is the world's leading solar concentrating technology (N.DKaushika 1993). Wu et al. (Shuang-YingWu et al. 2010) conducted a detailed analysis on solar thermal cavity receivers that used in electronic cooling equipment and houses. The solar parabolic trough collector output is significantly affected by heat loss due to wind velocity and direction (Reddy, Veershetty, and Vikram 2016). Using Python software, a mathematical model is provided to measure the heat transfer in a steady state in a parabolic trough collector (Polo et al. 2019); the thermal efficiency is better with nano-fluids containing a greater volume fraction of nanoparticles. Adriana and Estellé have numerically investigated the heat transfer behavior of carbon nano-fluids under laminar forced flow in horizontal pipes for different Re numbers (Adriana and Estellé 2018) and it was noticed that the convective heat transfer coefficient of nano-fluids is great for low Re numbers. Malviya et al (Malviya, Agrawal, and Baredar 2020) discussed an extensive study on the relationship between the cylindrical absorber material and different heat transfer fluids. The output of a small-scale parabolic trough solar with a thermal storage with a phase change material concentric tube has been studied using a numerical Computational Fluid Dynamics (CFD) model (Guerraiche et al. 2020) and it has been found that the average thermal efficiency of the solar concentrate parabolic trough increases by 6.56 percent. Heat transfer in the PTC solar system was simulated by the Open FOAM and ANSYS software, taking into account the thermal boundary layer plus Reynolds-Averaged NavierStokes (RANS) turbulence models. The Cross Linear Concentrated Solar Power (CL-CSP) thermal-hydraulic behavior in Tokyo was investigated (Mishra et al. 2021). A new two-phase closed flat heat pipe receiver with high temperature is suggested (Lin Yang et al. 2019) and experimentally investigated; theoretical and experimental studies show that the flat heat pipe receiver with sodium as working fluid has a good start-up efficiency. The thermal, hydraulic and economic characteristics of the preheating system and canopy PTC are examined numerically by Yang and Du (Liu Yang and Du 2020); the results show that the preheating system does not have a direct impact on the solar collector friction factor. The threedimensional numerical simulation model was performed in a Parabolic Trough Receiver (PTR) with molten salt as heat transfer fluid (HTF) using FLUENT software (Pina et al. 2017). Utilizing Monte-Carlo ray tracing 3D CFD model; El-bakry et al., (El-bakry, Kassem, and Hassan 2021) presented maps of both energetic and exergetic performance of parabolic trough concentrators and the results exhibited energy and energy increased efficiency from 85.76 to $86.40 \%$, as the irradiance grew from 200 to 1000 $\mathrm{W} / \mathrm{m}^{2}$. A three-dimensional model is constructed to simulate and evaluate the performance on a Parabolic Trough Receiver (PTR) with double tube and two HTF temperature distribution (P. Liu et al. 2021). Convective heat transfer Fe3O4-Therminol 66 Ferro-fluid is tested (Khosravi, Malekan, and Assad 2019) using computational fluid dynamics as the working fluids for a parabolic trough solar collector; the result showed that the local heat transfer coefficient of the collector tube, thermal efficiency as well as

*Corresponding e-mail: yara_mh2003@yahoo.com 
collector output temperature can be improved by using magnetic field. The effect of conical angle and insulation thickness on cavity receiver output using the CFD ANSYS 17.0 is studied (Zhang et al. 2020) and validated by comparison with experiment data using a hybrid optics and heat transfer model; the results showed that the optimal value of insulation thickness is $175 \mathrm{~mm}$, achieving 70.4 percent overall efficiency. A heat transfer model has been developed for a novel solar parabolic trough collection system with a V-shaped cavity absorber (Bie et al. 2020); the results of the analysis show that the model measurement error lies primarily in the effect of the variance of wind speed and the difference between the theoretical and real rate of increase in temperature with the sudden changes in solar Direct Normal Irradiation (DNI). A coupled simulation technique was used (Madadi, Rahimi, and Divband 2020) to solve the radiation, convection, and conduction heat transfer inside the solar water heating system of the parabolic trough collector (PTC); the location of the receiver pipe relative to the PTC significantly affects the thermal efficiency of the system and the absorber pipe's daily thermal efficiency is about $70 \%$.

The pipe flow measurement in the entrance region was explained by Kanda and Shimomukai (Kanda and Shimomukai 2009); at the inlet of the pipe there is a large pressure gradient in the radial direction and the wall pressure is lower than that for Re equals 5000 at the central core. The flow characteristics of multi-phase pipe flow were presented using the CFD method (L. Liu et al. 2019); the velocity was arch-like along the crosssection of the pipe with a high velocity near the middle and a low velocity near the wall. In a two-fluid horizontal circular pipe of slush nitrogen and slush hydrogen (Ohira et al. 2012), a three-dimensional numerical simulation on thermal non-equilibrium was constructed. In large-scale liquid natural gas (LNG) plants, spiral wound heat exchanges (SWHE) were the most commonly used; numerical simulations were performed on condensation flow and heat transfer for propane (S. Li et al. 2018b), ethane/propane mixture (S. Li et al. 2018a) based on two-fluid multiphase and k-turbulence models. In a porous pipe with an expanding or contracting wall, Zheng et al., (L. Li et al. 2017) studied the laminar flow concerned with multiple solutions of a single nonlinear Boundary Value Problem (BVP). Numerical mixed convection investigation in an inclined circular pipe is carried out (Al-asadi et al. 2017) using the finite volume method with nano-fluids ( $\mathrm{Al} 2 \mathrm{O} 3, \mathrm{CuO}$, and $\mathrm{SiO} 2)$; the surface temperature is increased as the angle of inclination of the pipe increases from the horizontal position in addition to the heat transfer using $\mathrm{SiO} 2$ nano-fluid is enhanced. Three-dimensional $\mathrm{k}-\varepsilon$ turbulent model is numerically simulated using CFD for the Syltherm fluid in solar system absorber tube (Ghasemi and Ranjbar 2017); thermo-physical properties are improved by adding the porous rings into the tubular solar absorber and decreasing the distance between the porous rings. A turbulent pipe flow numerical simulation is presented on both D3Q19 and D3Q27 using the Lattice Boltzmann Method (LBM) (Peng et al. 2018). Dutta et al., (Dutta et al. 2016) studied the flow separation features in pipe bends under high Reynolds number using the k$\varepsilon$ turbulence model; flow separation was observed with low curvature ratio by the movement of fluid from the inner to outer wall of the bend. For turbulent flow, a numerical investigation is carried out in a circular tube with pipe inserts (Tu, Wang, and Tang 2016); the heat transfer rate decreases with the increase in spacer length, and the flow resistance increases with the decrease in spacer length. There was a numerical study (Patro, Gupta, and Kumar 2015) of the heat transfer properties of pulsating turbulent flow in an air fluid pipe; the local $\mathrm{Nu}$ number of Reynolds decreased along the length of the pipe with partial variations in its values. The thermal essence of ethylene glycol-water ice slurrylflowing through a horizontal heated tube is studied numerically using Newtonian fluid (Onokoko et al. 2019). Using the immersed boundary process, Ardekani et al., (Ardekani et al. 2018) conducted computational simulations to investigate the heat transfer within a finite-size spherical particles in laminar pipe flows; heat transfer can be improved using spherical particles. A new phenomenological method to assessing laminar-turbulent pipe flow and parameter transition shows strong radial variations that are maximal at approximately the radial positions (Frigaard and Martinez 2009) where during the first stages of turbulent transition, puffs first appear. Heat transfer and friction factor characteristics of air flow in an inner twisted square duct and an outside circular pipe are experimentally tested (Bhadouriya, Agrawal, and Prabhu 2015) with a Reynolds numbers from 400 to 60,000 for. Using a CFD and experimentally, the axially induced swirling pipe flow characteristics and capabilities of a vane-type swirl generator were examined (Damiani, Carlos, and Moreira 2015); swirl flow leads to often higher friction factors compared to theoretical values of nonswirl. Swirling pipe flows are studied (Chin and Philip 2021) in order to understand the beginning of the inertial region; swirling causes a drag increase and the pipe has a new 'geometric' contribution in both axial and azimuthally directions that plays an important role in contributing to the dispersion of vortices in a swirling pipe flow's outer core region. The twophase swirling liquid flow in the cyclone with guiding vanes was numerically simulated using CFD (Kou, Chen, and Wu 2020); the reverse flow was unable to enter the overflow orifice, leading to stagnant separation efficiency, particularly for smaller droplets.

Given the above-mentioned studies, the related circular pipe absorber conditions of PTC were considered in only a few CFD studies, and no research was found to take into account the effect of climatic conditions and the impact of increasing heat flux on the pipe wall's internal environment compared to laminar and turbulent flow. A novel type of two-dimensional thermal CFD analysis solar-assisted PTC absorber/receiver pipe heating system was implemented in this paper by varying the flow type (from laminar to turbulent) and heat flux profiles in the tube to improve heat transfer rate. Firstly, there was a detailed description of the PTC thermal system. Second, in order to understand the efficiency of the system, the power flow and heat transfer models of the entire system, including the absorber, were developed. Thirdly, an absorber/receiver pipe CFD building model was developed. Fourthly, on the basis of the mathematical models suggested, the simulation analysis was illustrated. The current model can be used for medium-high temperature applications (between $290^{\circ} \mathrm{C}$ and $590^{\circ} \mathrm{C}$ ). The current CFD model is validated using analytical model that is derived and implemented using a MATLAB code. Finally, a distinction was presented between laminar and turbulent fluid flow. Therefore, this paper has four major objectives:

- Creation of solver and boundary conditions based on CFD ANSYS study the distributions of air velocity, temperature and pressure in PTC receiver circular pipe.

- Comparison between laminar and turbulent flow ( $\mathrm{k}-\varepsilon$ model) that affects the receiver pipe.

- Assessing the effect on the internal atmosphere of the pipe by rising the heat flux.

- Calculating drag, friction and heat transfer rate coefficients.

- Indicating Nusselt number expression to estimate the convection heat losses

- Validating the preset CFD model using analytical solution.

In the following sections, the paper is organized. Section 1 gives a brief idea of the PTC method, previous research work and motivation for the present work. The physical system description and the theoretical context required are found in section 2 . Section 3 includes numerical analysis of the geometric model and mesh grid system. In section 4, the parabolic trough mathematical model and governing equations for the CFD simulation are derived. Section 5 involves a thermal analysis with its effects on different parameters influencing the flow pattern of the receiver pipe followed by a review study bulletin in section 6 of the conclusions.

\section{PHYSICAL SYSTEM DESCRIPTION}

The PTC solar system is a technology that focuses on a focal line of solar thermal energy to transform it into heat $\left(550^{\circ} \mathrm{C}\right.$ can be attained) (Polo et al. 2019). A parabolic trough-shaped reflector, a metal receiver pipe surface, an evacuated glass envelope, a support structure, and a tracking device make up the PTC (Ghasemi and Ranjbar 2017). The reflector tends to focus direct solar radiation which it is the key to evaluate the PTC thermal efficiency and heats the transfer fluid in the tube onto the receiver placed at its focal line. This receiver consists of an absorber and a glass pipe cover that is coated with a selective surface for enhanced solar radiation absorption. The schematic of the solar parabolic system is shown in figure 
1 (a) ("Parabolic Trough Reflector," n.d.) and power flow diagram is shown in figure 1 (b) (Zayed et al. 2021).
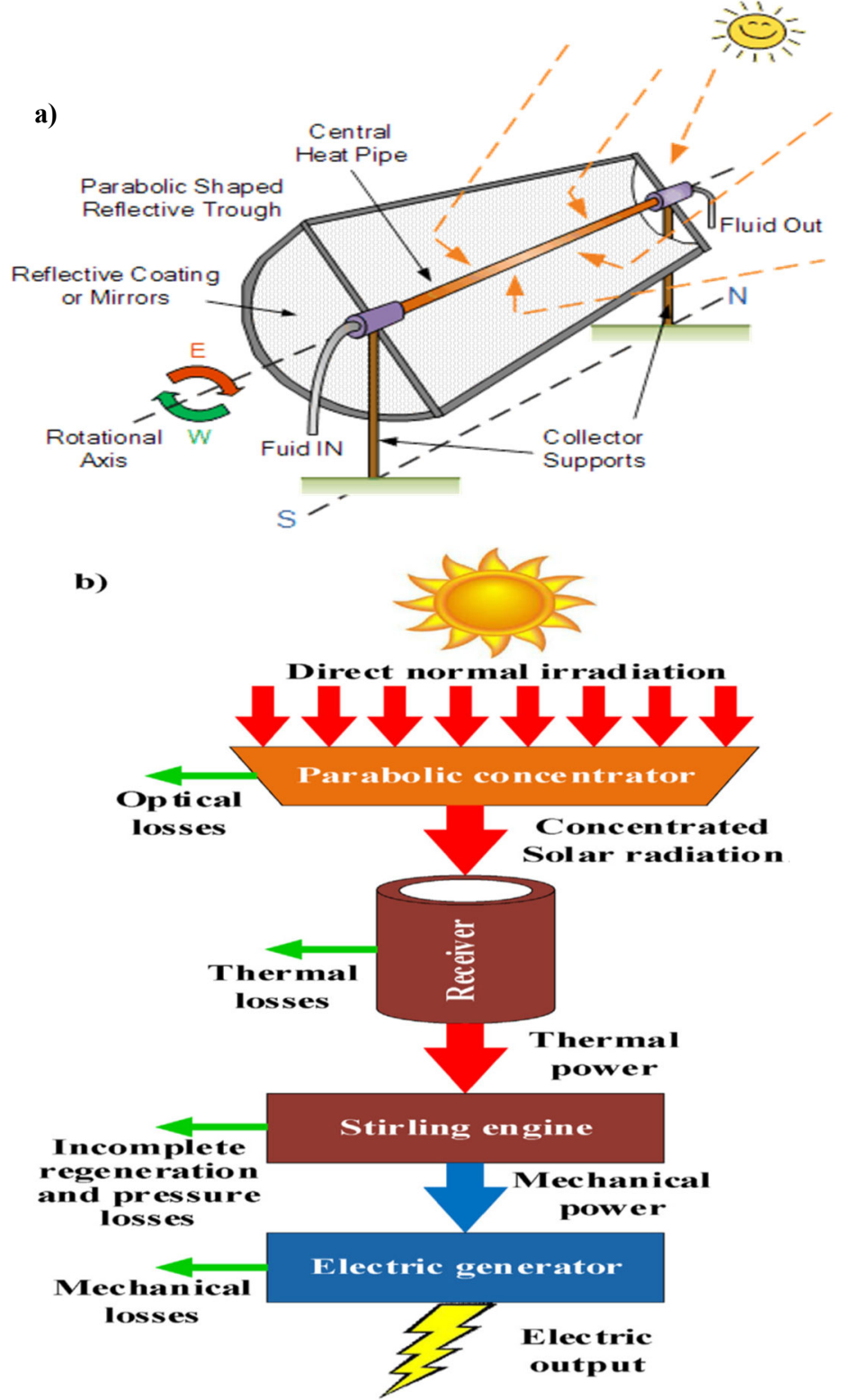

Fig. 1 (a) Schematic parabolic trough collector system ("Parabolic Trough Reflector," n.d.), (b) Power flow processing diagram of the PTC (Zayed et al. 2021)

Heat can transfer in three ways: conduction through solid materials, convection through fluids and radiation through a gas or the vacuum of space. The PTC's detailed heat transfer technique is as follows: (Zheng et al. 2019), (H. Liu et al. 2021): The incident solar radiation is reflected by the parabolic trough-shaped reflectors and focused on the heat collector; a little quantity of radiation is collected by the glass envelope, while the rest is transmitted through the receiver tube and absorbed. A portion of the absorption energy is transported into the heat transfer fluid via forced convection, while the remainder is returned to the glass envelope via natural convection and radiation. The heat transfer fluid, normally a mixture of water and other additives or thermal oil, is pumped through the tube and absorbs solar heat at temperatures above $200^{\circ} \mathrm{C}$ (XueChen et al. 20152). The energy from the receiver tube (convention and radiation) goes through the glass envelope and is lost to the atmosphere through convention and to the sky by radiation, coupled with the energy absorbed by the glass envelope. The geometry, orientation, and temperature conditions all affect the heat loss convection of a PTC receiver pipe.

\section{NUMERICAL ANALYSIS}

Tiny improvements in thermal efficiency can be a significant enhancement, so PTC is the majority of solar thermal energy systems used generally. Here, the thermal analysis focuses on the circular pipe of the absorber/receiver and discusses heat transfer convection through the pipeaffected fluids into two fluid types of laminar and turbulent as follow.

\subsection{Geometric Model}

Schott's PTR-70® HCE (El-bakry, Kassem, and Hassan 2021) is the selected PTC here as a physical model for the following optical and thermal flow simulations. The circular absorber/receiver pipe along its vertical axis is considered axis-symmetric; consequently, for numerical modeling, only a half-section of the absorber is applied. We set up a computational domain that is a two-dimensional slice from the axis to the wall pipe. The physical and geometry of receiver circular pipe are illustrated in figure 2 . The material of pipe is Aluminum and its dimensions are $4 \mathrm{~m}$ of length and 0.4 $\mathrm{m}$ of diameter.

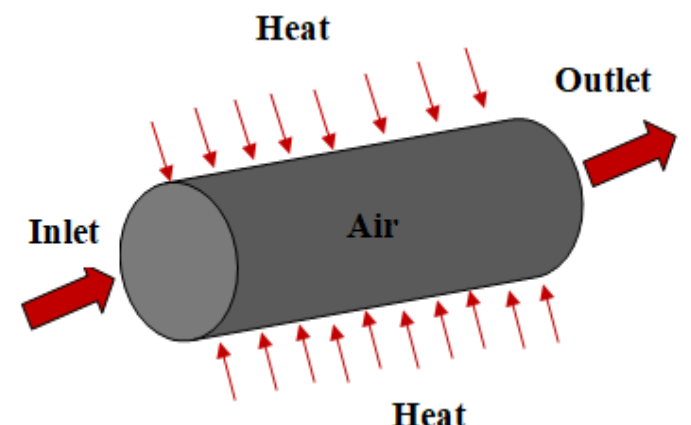

(a)

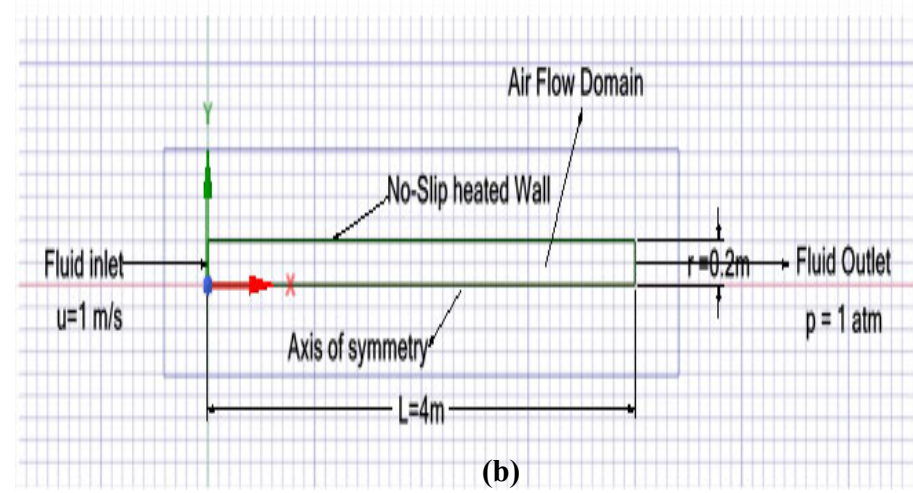

Fig. 2 (a) Physical absorber/receiver circular pipe/tube;

(b) Geometric model of receiver pipe

\subsection{Grid and Mesh Convergence System}

In the fluid domain, a standardized mesh of pipe was created, as shown in figure 3 . To ensure that $\mathrm{y}^{+}$less than 1 and assure computational accuracy, highly refined meshes are used in the boundary region near the inner and outer surfaces of the inner pipe and the inner surface of the absorber pipe, as indicated recently in section 6 of the grid validity model. A test based on the Grid Convergence Index (GCI) (El-bakry, Kassem, and Hassan 2021) was carried out to make sure the stability and convergence of the grid and the independence of the solution. Four grid sizes (coarse ' $c$ ', medium ' $m$ ', fine ' $f$ ' and accurate ' $a$ ') with 1800, 3600, 6000 and 8200 elements, respectively, are implemented and the fine-grid solution illustrates the best numerical uncertainty. Therefore, the grid system " $\mathrm{f}$ " of 6000 elements is applied here.

Boundary layer theory locates near wall pipe also taken into considerations of meshing system that affected of the outer layer of pipe. The boundary layer doesn't always remain laminar; it can become turbulent 
after this certain distance. The boundary layer thickness $\delta$ is calculated as following (Fan et al. 2011):

$$
\frac{\delta}{L}=\frac{5}{\sqrt{R e}} \sqrt{\frac{x}{L}}
$$

Where $\mathrm{L}$ is length of geometry, Re is called Reynolds Number, $\mathrm{x}$ : distance of developing flow. The thickness of boundary layer in this study is about $0.05 \mathrm{~m}$ (order of magnitude $10 e^{-2}$ ) for laminar flow and $0.1 \mathrm{~m}$ for turbulent flow.

\subsection{Parameter Definitions}

The Reynolds number represents the ration between the inertial force and friction force in a fluid. Flow in pipes classified into three categories (P. Liu et al. 2021):

- For $\operatorname{Re}<2300$ laminar flow

- For $2300<\operatorname{Re}<4000$ transition flow

- For $4000<\operatorname{Re}$ Turbulent flow

Reynolds number $(\mathrm{Re})$, average heat transfer coefficient $\left(\mathrm{H}_{\mathrm{f}}\right)$, average Nusselt number $\left(\mathrm{N}_{\mathrm{u}}\right)$, drag coefficient $\left(\mathrm{C}_{\mathrm{d}}\right)$ and friction factor $\left(\mathrm{F}_{\mathrm{r}}\right)$ are defined and calculated as below (P. Liu et al. 2020):

$$
\begin{array}{ll}
\mathrm{Re}=\frac{\rho u d}{\mu} & \text { (2), } \mathrm{H}_{\mathrm{f}}=\frac{q w}{(T w-T f)} \quad \text { (3), } \mathrm{N}_{\mathrm{u}}=\frac{h d}{\lambda} \\
\mathrm{C}_{\mathrm{d}}=\frac{d}{\frac{1}{2} \rho u^{2} A} & \text { (5), and } \mathrm{F}_{\mathrm{r}}=\frac{2 \Delta P l d}{\rho u^{2}}
\end{array}
$$

Where $\rho$ is the fluid density; $\mathrm{u}$ is the velocity at pipe inlet; $\mathrm{d}$ is diameter of pipe, $\boldsymbol{\mu}$ is the fluid viscosity, $\mathrm{T}_{\mathrm{f}}$ is the bulk temperature of the heating temperature fluids and $\lambda$ is thermal conductivity of fluid at $T_{f}$. The temperature and average heat flux on the inner surface of the inner pipe or the inner surface of the absorber/receiver tube, respectively, are represented by $\mathrm{Tw}$ and qw. $\Delta \mathrm{Pl}$ is the pressure drop per unit distance in the flow direction, and $\mathrm{A}$ is projection pipe area $=2 \pi r \mathrm{~L}$ (r: pipe radius, $\mathrm{L}$ : pipe length).

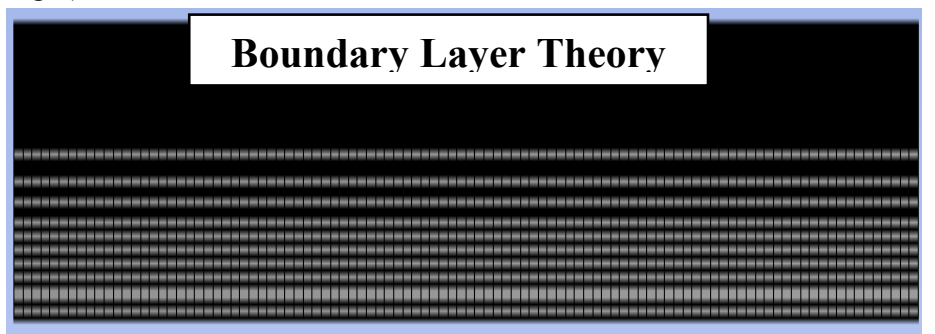

Fig. 3 View of pipe inserts mesh with computational grid using ANSYS

\section{MATERIALS AND METHODS}

\subsection{Governing Equations for CFD Solution}

Mass conservation, momentum conservation and energy conservation are usually expressed using Navier-Stokes equations (Dutta et al. 2016), (Jae et al. 2019). The governing equations of this CFD thermal convection study can be expressed as follows:

The conversation of mass-continuity equation:

$$
\frac{d u}{d x}+\frac{d v}{d y}=0
$$

The conversation of momentum equation

$\mathrm{x}$ - direction: $\frac{d}{d x}(\rho u u)+\frac{d}{d y}(\rho v u)=-\frac{d p}{d x}+\frac{d}{d x}\left(\mu \frac{d u}{d x}\right)+\frac{d}{d y}\left(\mu \frac{d u}{d y}\right)$

$\mathrm{y}-\operatorname{direction}: \frac{d}{d x}(\rho u v)+\frac{d}{d y}(\rho v v)=-\frac{d p}{d y}+\frac{d}{d x}\left(\mu \frac{d v}{d x}\right)+\frac{d}{d y}\left(\mu \frac{d v}{d y}\right)$

The conversation of energy equation

$\rho c p\left(\frac{d T}{d t}+\frac{d(u T)}{d x}\right)=\frac{d}{d x}\left(\lambda \frac{d T}{d x}\right)+\mu \phi$

Where $\rho$ and $p$ are fluid density and pressure, respectively; $c p$ and $T$ are heat and temperature specific to fluids, respectively; $\mu$ and $\lambda$ are the fluid viscosity and thermal conductivity, respectively in addition $\phi$ represents the absorbed energy. The RNG group of $\mathrm{k}-\varepsilon$ turbulence model (Launder 2017), (I and I 1986) is used in this study as follows:

$$
\begin{aligned}
& \frac{d}{d x}(\rho k u)=\frac{d}{d x}\left(\left(\mu+\frac{\mu t}{\sigma k}\right) \lambda \frac{d k}{d x}\right)+G k-\rho \varepsilon \\
& \frac{d}{d x}(\rho \varepsilon u)=\frac{d}{d x}\left(\left(\mu+\frac{\mu t}{\sigma \varepsilon}\right) \lambda \frac{d k}{d x}\right)+C 1 \frac{\varepsilon}{k} G k-C 2 \rho \frac{\varepsilon^{2}}{k} \\
& \mu_{t}=c \mu \rho \frac{k^{2}}{\varepsilon}(13), G_{k}=\mu t \frac{d u}{d y}\left(\frac{d u}{d y}+\frac{d v}{d x}\right)
\end{aligned}
$$

Where $\sigma_{\varepsilon}, \sigma_{\mathrm{k}}, \mathrm{c}_{\mu}, \mathrm{c}_{1}, \mathrm{c}_{2}$ are constants

\subsection{Boundary conditions}

The PTC receiver pipe is subject to different boundary conditions in this CFD model: a constant temperature condition is imposed on the stationary non-slip pipe wall; a fully developed flow and temperature boundary condition are applied at the tube inlet, with the fully developed flow velocity and temperature profiles contained by repeatedly calculating the flow through a smooth tube, ignored by heat conduction and radiation in the pipe. The gauge atmospheric pressure is equal to the pressure at the exit. The temperature of the working fluid rises steadily from input to outlet, and the temperature of the receiver wall surface is thought to be the same as that of the working fluid in relation to solar flux.

\subsection{CFD Simulation using ANSYS Fluent}

Computational fluid dynamics (CFD) is a technique of extraordinary efficiency, precision and application breadth. ANSYS Fluent is the industry-leading programmed for turbo-machinery applications in computational fluid dynamics, including pumps, fans, tubing, compressors and gas and hydraulic turbines (Canonsburg 2015). A simulation of the system must be conducted by performing a series of steps that include problem detection, boundary conditions, meshing, outcomes and results interpretation. This numerical simulation is implemented using ANSYS 2020 R1 commercial CFD package to investigate the heat transfer phenomenon in the receiver pipe of PTC solar system through the Finite Volume Method (FVM). The distribution of heat flux is applied as a volume heat source inside a small layer outside the tube via laminar and turbulent flow fluids, and a two-dimensional model of receiver pipe double accuracy is built using ANSYS meshing as the solver. The following assumptions of this grid model of 6000 elements are:

- The heat transfer cycle for domain flow is an incompressible steady state condition.

- The flow is assumed laminar for $\mathrm{Re}=272$ and turbulent for $\mathrm{Re}=27200$.

- The pipe walls are subjected to a heat flux of $40 \mathrm{~W} / \mathrm{m} 2$.

- The working fluid is air with inlet velocity of $1 \mathrm{~m} / \mathrm{s}$.

- The air has a density of $1.225 \mathrm{~kg} / \mathrm{m} 3$; viscosity of $1.8 \mathrm{e}-2$ in laminar and viscosity of $1.8 \mathrm{e}-5$ in turbulent flow; temperature of $300 \mathrm{oK}$; a specific heat of $1000 \frac{\mathrm{J}}{\mathrm{kg} \cdot \mathrm{k}}$; and thermal conductivity of $0.02 \frac{\mathrm{W}}{\mathrm{m} \cdot \mathrm{k}}$ (Shpilrain 2011).

- The total thickness of the pipe wall boundary layer is $0.05 \mathrm{~m}$ in laminar and $0.1 \mathrm{~m}$ in turbulent flow, based on the boundary layer theory.

- For all the analyses, the convergent residual is taken as $10^{-5}$.

\section{VALIDATION}

\subsection{Grid Validity Numerical Model}

A careful check of the grid dependency of the numerical solutions is carried out to ensure the accuracy and validity of the numerical results by considering four grid systems with a large number of grid points, i.e., 1800, 3600,6000 and 8200 elements at $\mathrm{Re}=272$ of laminar and 27200 of turbulent flow. The averaged Nusselt number and maximum outlet velocity on these four grid systems are listed in table 1 . It is found that the relative deviations of averaged Nusselt numbers between grid 3 and grid 4 are only $0.4 \%$ in laminar and $0.3 \%$ in turbulent flow. Also, the deviations of maximum outlet velocity between grid 3 and grid 4 are $0.5 \%$ in laminar and $0.49 \%$ in turbulent flow. The 6000 -element grid architecture was chosen to conserve 
computing resources and strike a compromise between computational economy and prediction accuracy..

Table.1 Grid independence test

\begin{tabular}{c|cccc}
\hline \multirow{2}{*}{$\begin{array}{c}\text { Grid } \\
\text { Elements }\end{array}$} & \multicolumn{2}{|c}{ Laminar Flow } & \multicolumn{2}{c}{ Turbulent Flow } \\
\cline { 2 - 5 } & $\begin{array}{c}\text { Nusselt } \\
\text { Number }\end{array}$ & $V_{\text {outlet }}$ & $\begin{array}{c}\text { Nusselt } \\
\text { Number }\end{array}$ & $V_{\text {outlet }}$ \\
\hline 1800 & 390 & 1.67254 & 880 & 0.95673 \\
3600 & 456 & 1.85877 & 940 & 1.09842 \\
6000 & 500 & 1.92563 & 1000 & 1.15343 \\
8200 & 503 & 1.93542 & 1003 & 1.15932 \\
Baseline & & & & \\
\hline
\end{tabular}

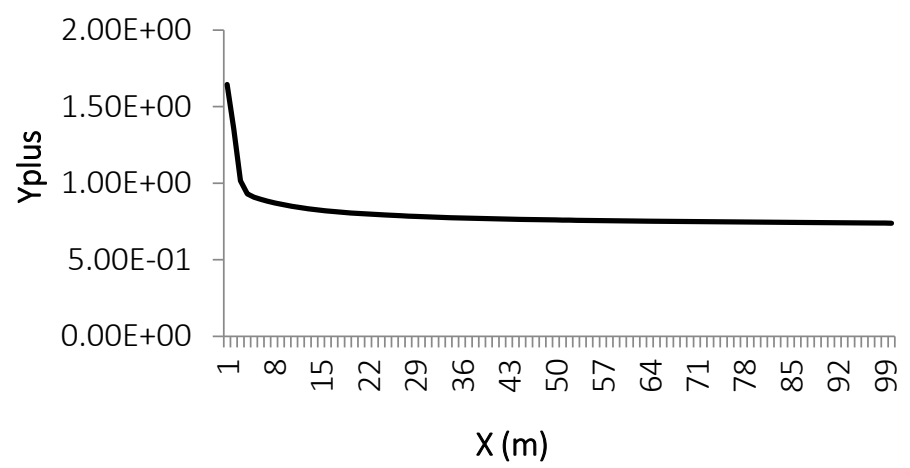

Fig. $4 \mathrm{Y}^{+}$Accuracy model

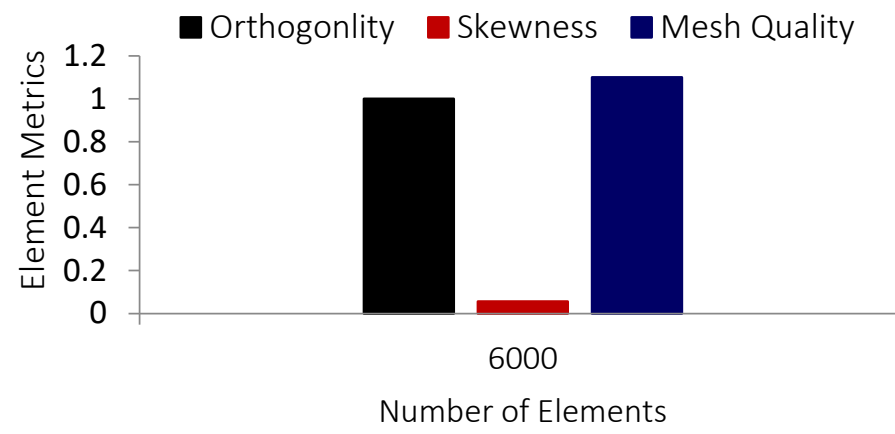

Fig. 5 Quality elements of numerical model of PTC receiver pipe

From figure 5; it is found that most of grid elements have orthogonlity equal 1 , skewness equal 0 and mesh quality around 1 . So, this model has validated quality grid system. We validated the current analytical model in the following part by comparing its results to those found in the literature (EvangelosBellosChristosTzivanidisKimon A.Antonopoulos 2017).

\subsection{Validation Model}

To validate the parabolic trough mathematical model we compared the results of the present model with the results available in reference (EvangelosBellosChristosTzivanidisKimon A.Antonopoulos 2017) for the case of pressurized water. The model parameters are defined in table 2 . The model validation results are listed in table 3 . Table 3 illustrates the accuracy of the present model in which its results are correlated well with the results of reference (EvangelosBellosChristosTzivanidisKimon A.Antonopoulos 2017). Table 4 tabulates the results of the analytical solution in comparison to the results of the CFD analysis.

These results determine the accuracy of the CFD model. The difference between the analytical and numerical simulation the thermal efficiency is about $0.51 \%$ while in the exit temperature is $2.7 \%$. The analytical results are obtained for 0.9 optical efficiency. It is worth noting that; the decrease of the optical efficiency to 0.8 decreases the thermal efficiency to 0.6624 and decreases the outlet temperature to $316.6 \mathrm{~K}$. So, the optical efficiency has a significant effect of the parabolic trough thermal efficiency the outlet temperature.

Table 2 Parameters for pressurized water validation model

\begin{tabular}{|c|c|c|c|}
\hline Reference parameters & Value & Reference parameters & Value \\
\hline $\begin{array}{l}\text { Emissivity of receiver } \\
\text { tube }\left(\epsilon_{\mathrm{r}}\right)\end{array}$ & 0.095 & Tube length (L) & $12 \mathrm{~m}$ \\
\hline $\begin{array}{l}\text { Emissivity of glass } \\
\text { cover }\left(\epsilon_{c}\right)\end{array}$ & 0.88 & Reflector width (W) & $5.8 \mathrm{~m}$ \\
\hline $\begin{array}{l}\text { Optical efficiency } \\
\left(\eta_{\text {opt }}\right)\end{array}$ & 0.8 & Reflector radius (f) & $1.71 \mathrm{~m}$ \\
\hline $\begin{array}{l}\text { Solar beam irradiation } \\
\left(G_{b}\right)\end{array}$ & $800 \frac{\mathrm{w}}{\mathrm{m}^{2}}$ & $\begin{array}{l}\text { Thermal conductivity } \\
\text { (k) }\end{array}$ & $0.628 \frac{\mathrm{W}}{\mathrm{mK}}$ \\
\hline $\begin{array}{l}\text { Sun temperature } \\
\left(\mathrm{T}_{\text {sun }}\right)\end{array}$ & $5770 \mathrm{~K}$ & Density $(\rho)$ & 994 \\
\hline $\begin{array}{l}\text { Ambient temperature } \\
\left(\mathrm{T}_{\mathrm{am}}\right)\end{array}$ & $300 \mathrm{~K}$ & $\begin{array}{l}\text { specific heat coefficient } \\
\text { at constant pressure }\left(C_{p}\right)\end{array}$ & $4164 \frac{\mathrm{J}}{\mathrm{kgK}}$ \\
\hline $\begin{array}{l}\text { Outlet convection } \\
\text { coefficient }\left(\mathrm{h}_{\text {out }}\right)\end{array}$ & $10 \frac{\mathrm{W}}{\mathrm{m}^{2} \mathrm{~K}}$ & Dynamic viscosity $(\mu)$ & $5.9 \times 10^{-4} \mathrm{~Pa}$ \\
\hline
\end{tabular}

Table 3 Model validation outputs

\begin{tabular}{|c|c|c|c|}
\hline $\mathrm{T}_{\mathrm{in}}[\mathrm{K}]$ & $\begin{array}{c}\text { Output } \\
\text { parameter }\end{array}$ & $\begin{array}{c}\text { Bellos } \\
\text { 2017(EvangelosBellosC } \\
\text { hristosTzivanidisKimon } \\
\text { A.Antonopoulos 2017) }\end{array}$ & $\begin{array}{c}\text { Present } \\
\text { analytical model }\end{array}$ \\
\hline \multirow{3}{*}{300} & $\mathrm{~T}_{\text {out }}[\mathrm{K}]$ & 305.3 & 305.35 \\
\hline & $\eta_{\text {th }}$ & 0.7881 & 0.7997 \\
\hline & $\mathrm{h}\left[\frac{\mathrm{W}}{\mathrm{m}^{2} \mathrm{~K}}\right]$ & 2309 & 2443.8 \\
\hline \multirow{3}{*}{400} & $\mathrm{~T}_{\text {out }}[\mathrm{K}]$ & 405.2 & 405.18 \\
\hline & $\eta_{\text {th }}$ & 0.7835 & 0.7952 \\
\hline & $\mathrm{h}\left[\frac{\mathrm{W}}{\mathrm{m}^{2} \mathrm{~K}}\right]$ & 4205 & 4403.2 \\
\hline \multirow{3}{*}{500} & $\mathrm{~T}_{\text {out }}[\mathrm{K}]$ & 504.8 & 504.61 \\
\hline & $\eta_{\text {th }}$ & 0.774 & 0.7858 \\
\hline & $\mathrm{h}\left[\frac{\mathrm{W}}{\mathrm{m}^{2} \mathrm{~K}}\right]$ & 5336 & 5581.1 \\
\hline
\end{tabular}

Table 4 Analytical results comparing to CFD solution

\begin{tabular}{ccc}
\hline Parameter & Analytical solution & $\begin{array}{c}\text { CFD } \\
\text { analysis }\end{array}$ \\
\hline $\begin{array}{c}\text { Thermal efficiency } \\
\text { outlet temperature } \\
\text { (turbulent) }\end{array}$ & 0.7362 & 0.74 \\
& $318.49 \mathrm{~K}$ & 310 \\
\hline
\end{tabular}

\section{RESULTS AND DISCUSSION}

The numerical simulation is carried out for the solar parabolic collector absorber/receiver tube under various well formed flow conditions, which includes 1000 iterations in laminar flow to stabilize the heat transfer cycle before switching to turbulent flow. The results indicate that the convergence of continuity, momentum and energy occurred after eighty iterations with residual of $10^{-5}$. Contours of velocity, pressure and temperature fields and of the absorber tube for laminar and turbulent flows are presented. The velocity contours of absorber tube for laminar flow is shown in figure 6-a; while figure 6-b illustrates velocity contour for turbulent flow.

The pressure contours of absorber tube for laminar flow is shown in figure 7-a; while figure 7-b illustrates pressure contour for turbulent flow. The temperature contours of absorber tube for laminar flow is shown in figure 8-a; while figure 8-b illustrates temperature contour for turbulent flow. The velocity vector of absorber tube for laminar flow is shown in figure 9-a; while figure 9-b illustrates velocity vector for turbulent flow. 


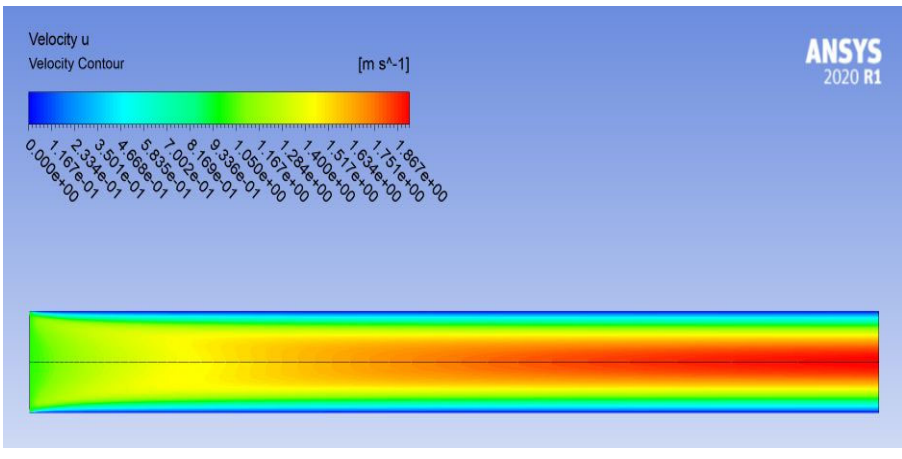

(a) Laminar Flow

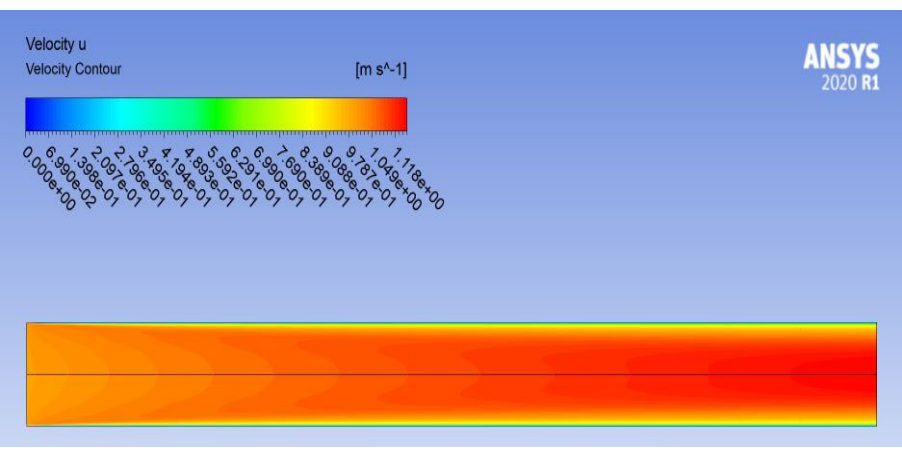

(b) Turbulent Flow

Fig. 6 Velocity contours of absorber tube for different fully developed flow conditions

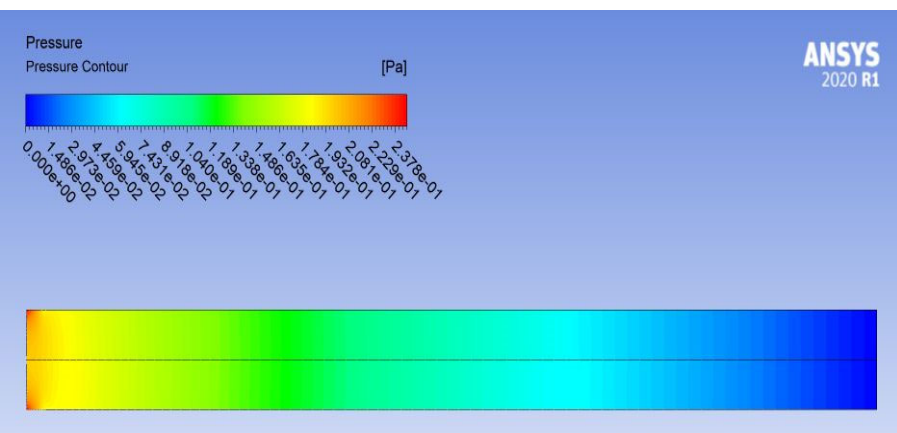

(a) Laminar Flow

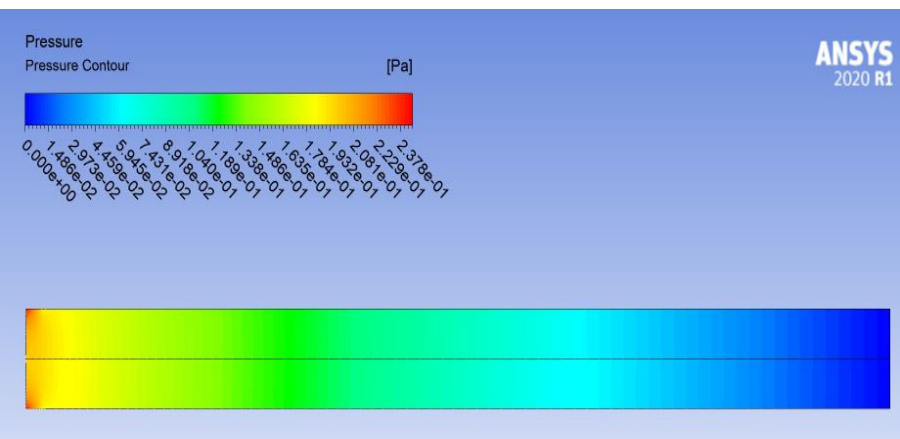

(b) Turbulent Flow

Fig. 7 Pressure contours of absorber tube for different fully developed flow conditions

It is obvious from figure 6 that the maxium velocity is $1.92563 \mathrm{~m} / \mathrm{s}$ for laminar and $1.15343 \mathrm{~m} / \mathrm{s}$ for turbulent flow. With a low velocity near the inlet and a high velocity near the exit, the velocity along the cross-section of the pipe was attachment point. From figure 7; the maxium pressure is $2.5678 \mathrm{~Pa}$ for laminar and 0.245237 for turbulent flow. Near the inlet of the pipe, there is a wide pressure gradient in the radial direction and the pressure gradient is induced by the radial portion of the vortex curl, which decreases as Re increases. From figure 8; the maxium temperature is $344.061^{\circ} \mathrm{k}$ for laminar and $310.819{ }^{\circ} \mathrm{k}$ for turbulent flow. Velocity distribution chart at absorber wall for laminar and turbulent flows is presented in figure 10 while temperature distribution chart is described in figure 11 . The velocity drop chart along center line axis of absorber pipe is shown in figure 12 for laminar and turbulent flows. Also, pressure drop chart is shown in figure 13 for laminar and turbulent flows. In addition, temperature drop chart is shown in figure 14 for air flow.

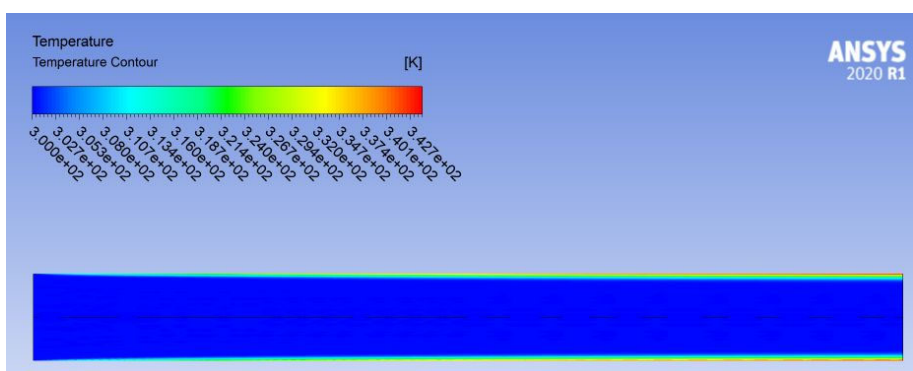

(a) Laminar Flow

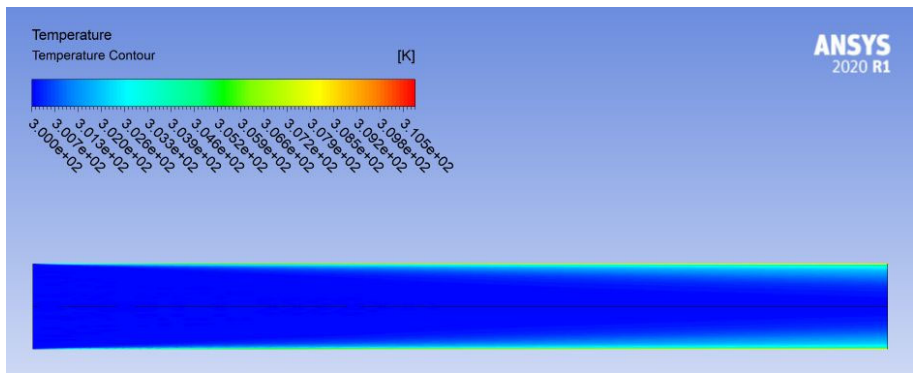

(b) Turbulent Flow

Fig. 8 Temperature contours of absorber tube for different fully developed flow conditions

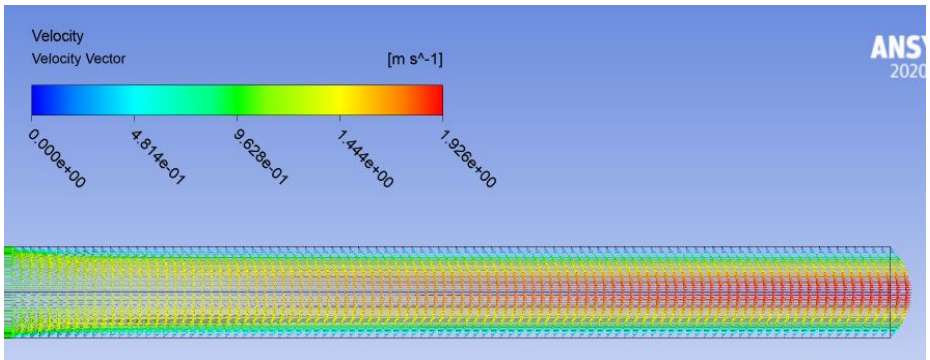

(a) Laminar Flow

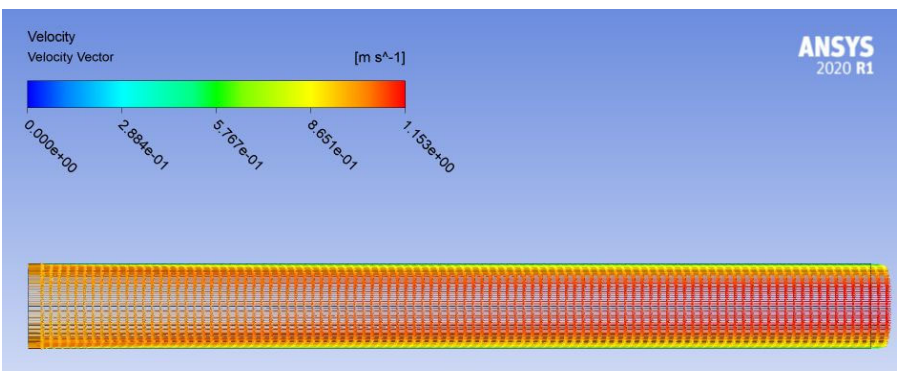

(b) Turbulent Flow

Fig. 9 Velocity Vector of absorber tube for different fully developed flow conditions 


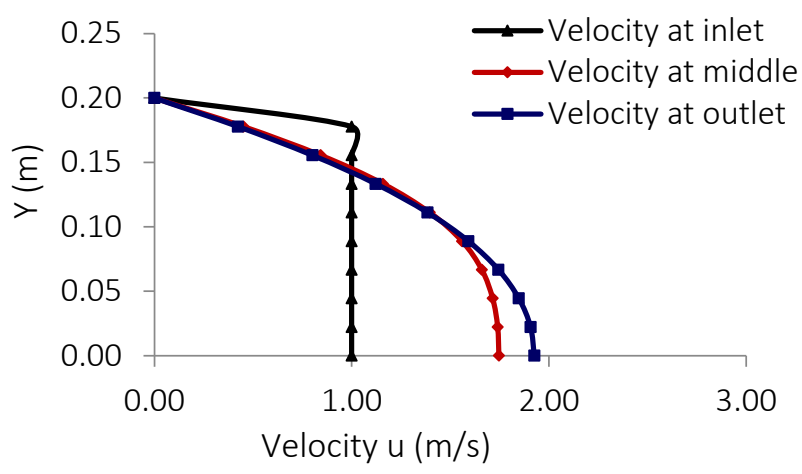

(a) Laminar Flow

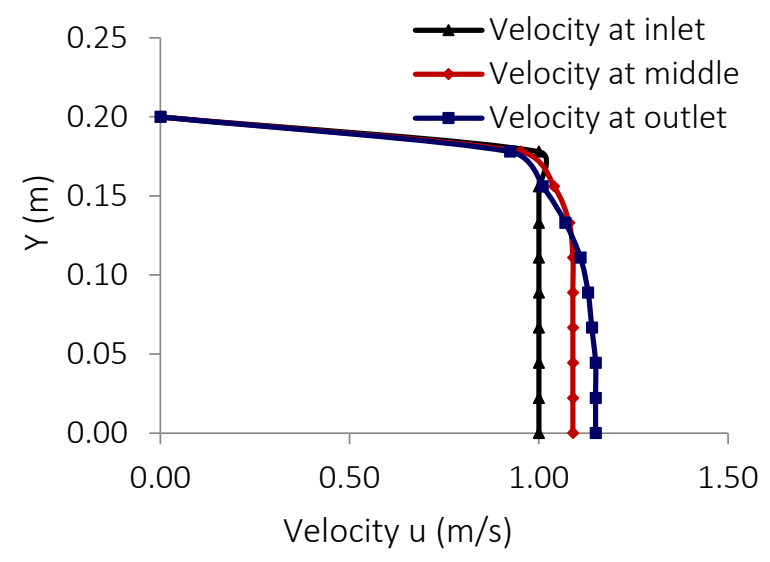

(b) Turbulent Flow

Fig. 10 Velocity profile chart at wall of absorber tube for different flow conditions

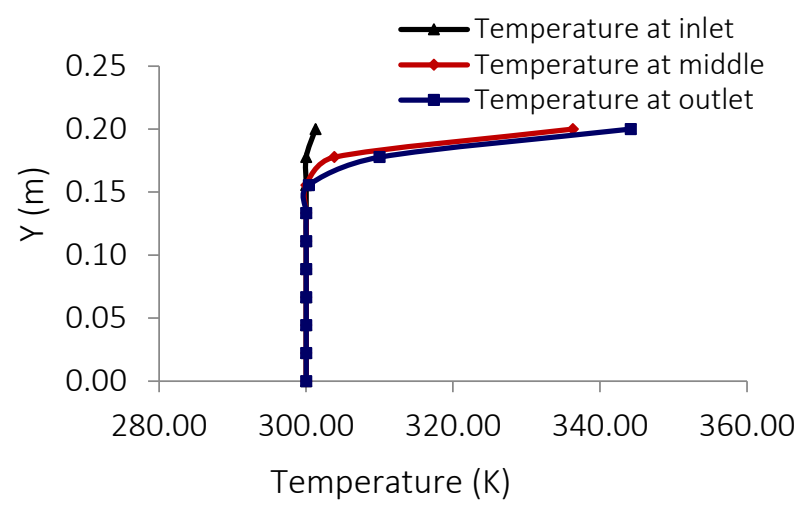

(a) Laminar Flow

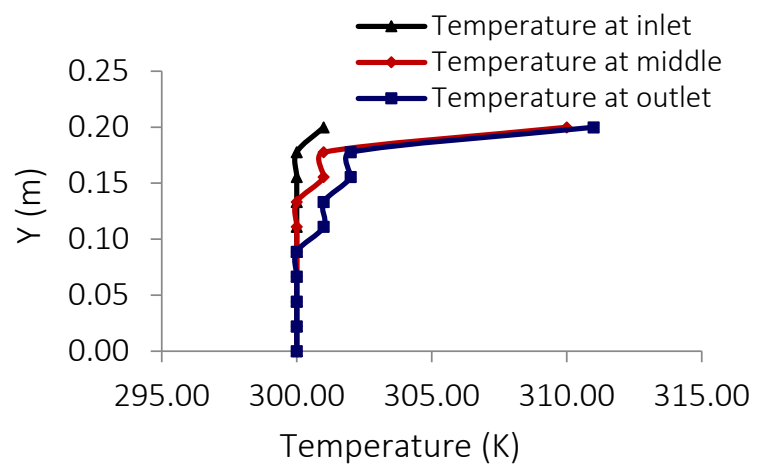

(b) Turbulent Flow

Fig. 11 Temperature profile chart at wall of absorber tube for different flow conditions

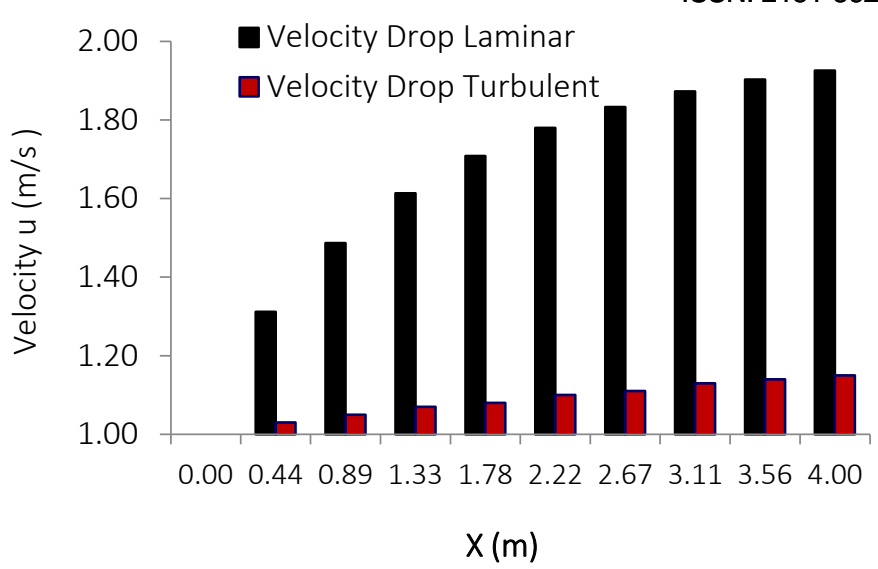

Fig.12: Longitude velocity drop chart at wall of absorber tube for different flow conditions

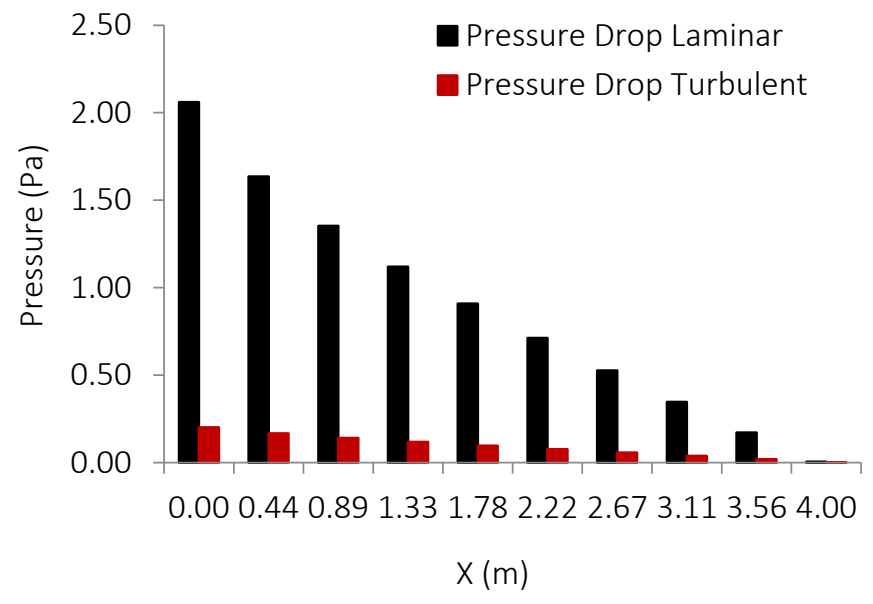

Fig.13: Longitude pressure drop chart at wall of absorber tube for different flow conditions

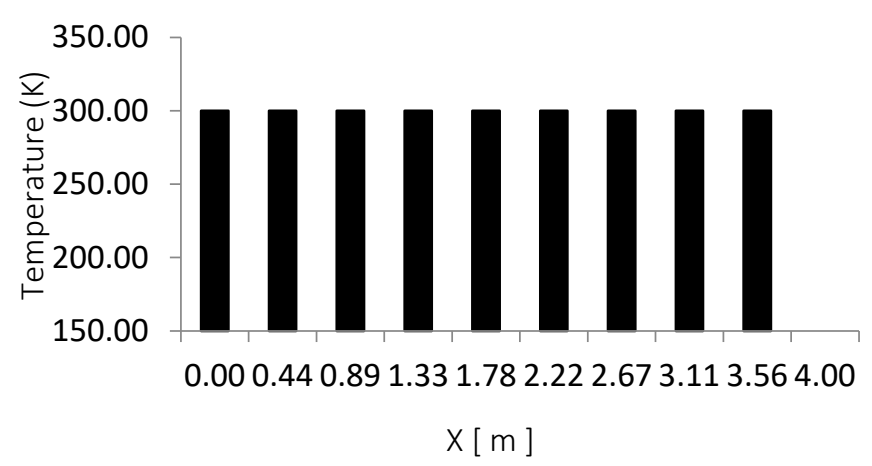

Fig.14: Longitude temperature drop chart at wall of absorber tube for air flow

From figure 12; it is clear the velocity drop increases with increasing distance along center line axis towards outlet line of receiver pipe. Also; velocity drop distribution for laminar flow is higher than the velocity drop in turbulent flow. As seen in figure 13; the pressure drop decreases with increasing distance along center line axis towards outlet line of receiver pipe and pressure drop distribution for laminar flow is higher than the pressure drop in turbulent follow. In figure 14; it is found temperature distribution almost constant along center line receiver pipe in laminar and turbulent flows. Figure 15 shows heat transfer coefficients distribution for laminar and turbulent flows. Also, surface Nusselt numbers charts estimated for different flows of laminar and turbulent flow in figure 16. Drag coefficient chart of laminar and turbulent flows is illustrated in figure 17. Figure 18 presents skin friction coefficient chart of turbulent flow. 


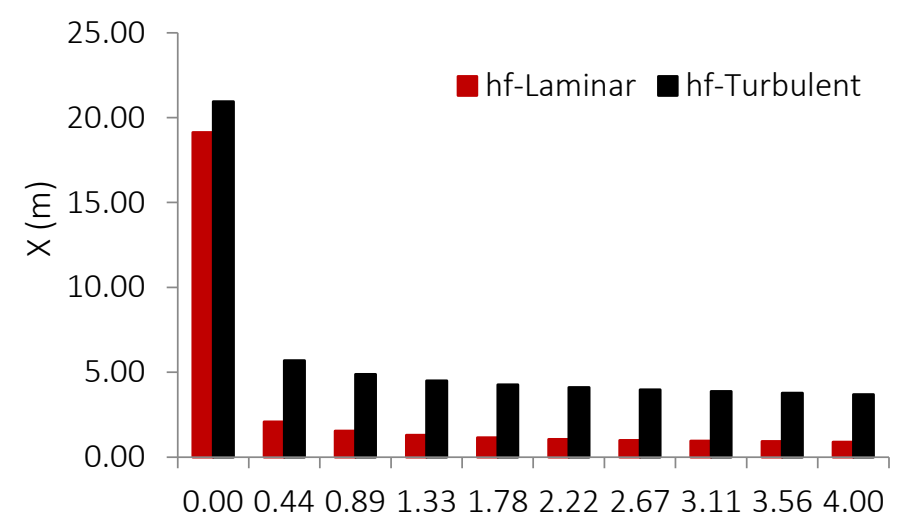

\section{Surface Heat Transfer Coefficient $\left(\mathrm{W} / \mathrm{m}^{2} \mathrm{~K}\right)$ ]}

Fig. 15 Heat transfer coefficient of absorber tube for different flow conditions

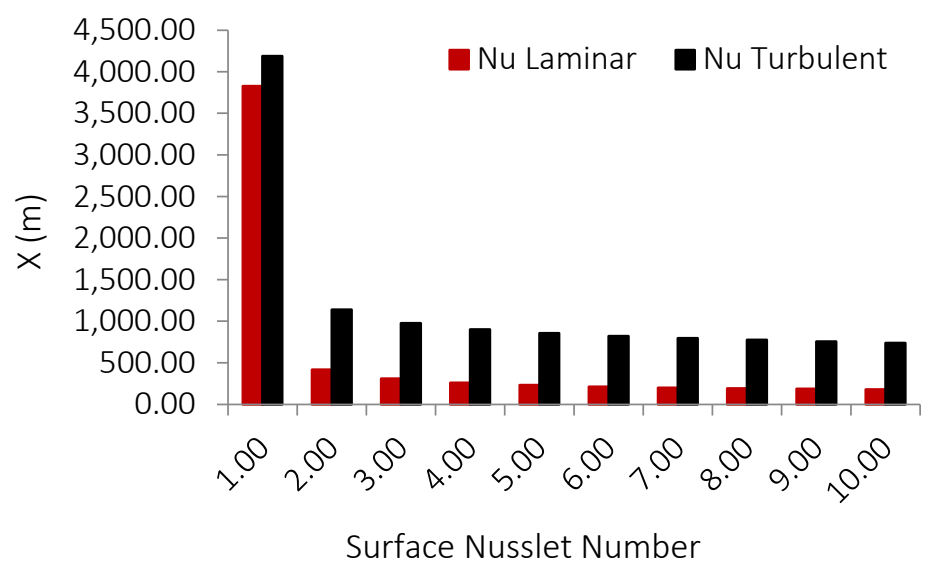

Fig. 16 Nusselt Number of absorber tube for different flow conditions

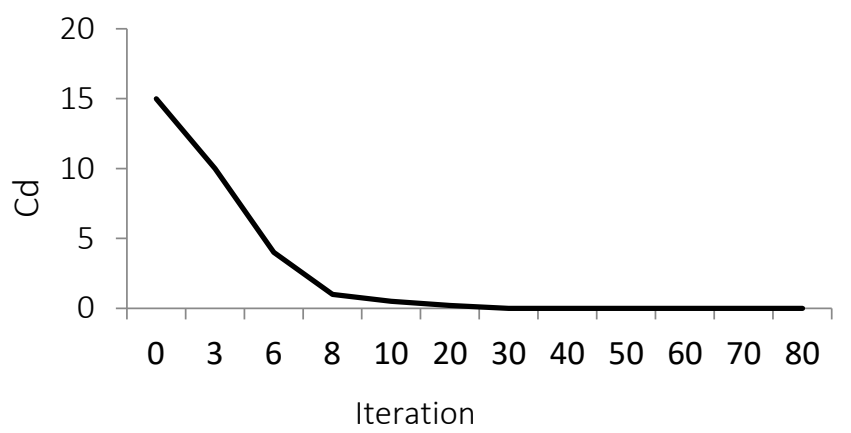

(a) Laminar Flow

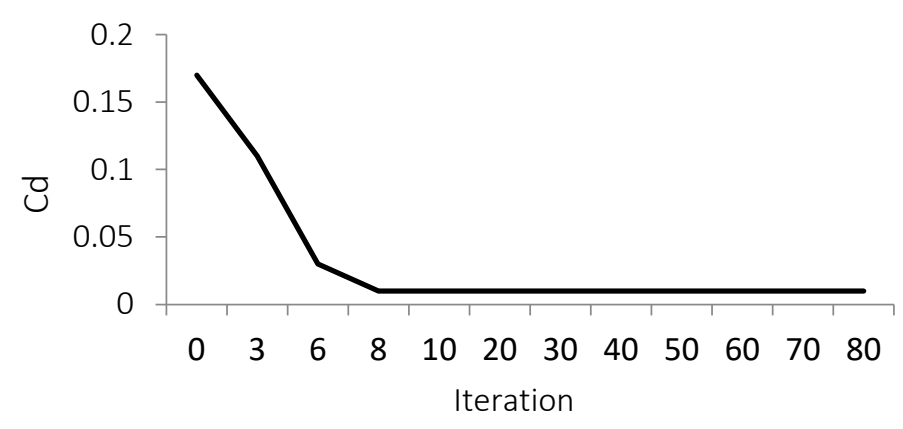

(b) Turbulent Flow

Fig.17 Drag coefficient of absorber tube for different flow conditions

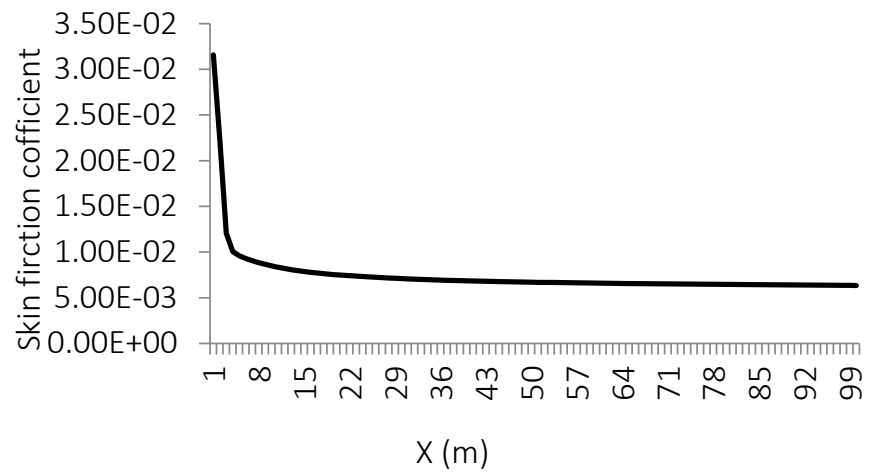

Fig.18 Skin friction coefficient chart of absorber tube for turbulent flow condition

It is noticed from figure 15; the heat transfer coefficient is higher value in turbulent flow $\left(6 \mathrm{~W}^{-2} \mathrm{k}^{-1}\right)$ than laminar flow $\left(3 \mathrm{~W}^{-2} \mathrm{k}^{-1}\right)$ since this coefficient increases with increasing of Reynolds number. Simultaneously in figure 16, Nusselt number value in turbulent flow (1000) is higher than it in laminar flow (500). From figure 17; it is clear that drag coefficient decreases when Reynolds number increases (0.07589 for laminar and 0.00733 for turbulent). Skin friction coefficient decreases with increasing of Reynolds number as illustrated in figure 18 (0.01 of turbulent). Taking into account the Nusselt number and the friction factor, the thermal efficiency factor is also assessed; the collector layout should be designed to transfer maximum heat energy to the moving fluid with minimal fan energy consumption. The thermal performance factor $(\eta)$ applied is given in Eq. (15) (Ghasemi and Ranjbar 2017). In this laminar model; it is found that thermal performance factor of PTC is $74 \%$.

$$
\eta=\frac{N u}{F r}
$$

The effect of increasing heat flux $\left(80 \mathrm{~W} / \mathrm{m}^{2}\right)$ on the thermal efficiency of the parabolic collector in the absorber tube is being studied. When increasing heat flux at wall of PTC receiver pipe, the temperature wall increases as shown in figure 19 (a) for laminar and (b) for turbulent flow.

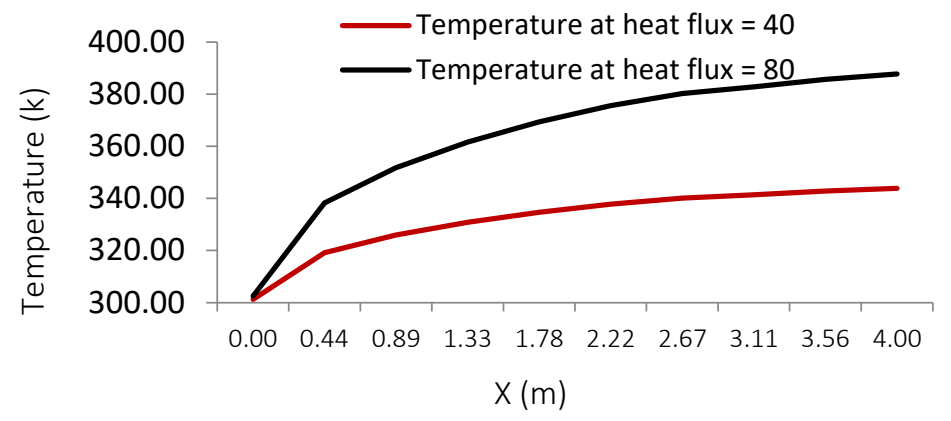

(a) Laminar Flow

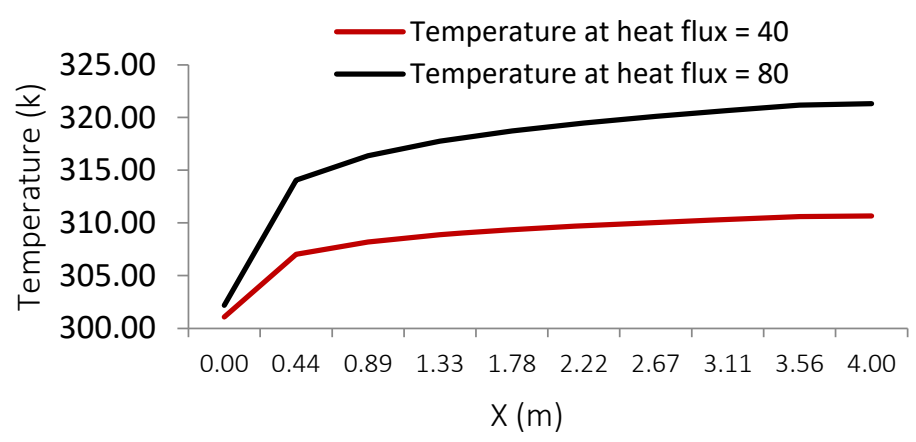

(b) Turbulent Flow

Fig. 19 Temperature distribution of various heat fluxes at wall line of PTC receiver for flow conditions 
From figure 19; it is clear that the temperature at wall increases with increasing of heat flux. It is increased from 350 to $390 \mathrm{~K}$ in laminar flow and from 310 to $325 \mathrm{~K}$ in turbulent flow. With the decrease in heat flux, the outlet flow velocity also increases, while the pressure drop increases with the decrease in heat flux.

\section{CONCLUSIONS}

Solar heating systems are an appealing candidate in the building sector, with growing concerns about energy efficiency and environmental protection. Due to wind velocity and speed, solar parabolic dish collector output is significantly impacted by heat loss. In the current study, a two-dimensional thermal study was conducted to investigate the heat transfer and air flow characteristics within the circular pipe of the PTC solar system absorber/receiver. In this study, a numerical simulation of the fully developed laminar and turbulent flow steady state condition for 1000 iterations is applied plus heat transfer in receiver tube pipe. The following conclusions have been drawn:

- The results indicate that the convergence of continuity, momentum and energy occurred after eighty iterations with residual of $10^{-5}$.

- Velocity drop increases with increasing distance along center line axis towards outlet line of receiver pipe. Plus; velocity drop distribution for laminar flow is higher than the velocity drop in turbulent flow. The maxium velocity is $1.92563 \mathrm{~m} / \mathrm{s}$ for laminar flow and $1.15343 \mathrm{~m} / \mathrm{s}$ for turbulent flow.

- Pressure drop decreases with increasing distance along center line axis towards outlet line of receiver pipe and pressure drop for laminar flow is higher than the pressure drop in turbulent follow. The maxium pressure is $2.5678 \mathrm{~Pa}$ for laminar flow and 0.245237 for turbulent flow.

- It is found temperature distribution almost constant along center line receiver pipe in laminar and turbulent flows. That means the center line of receiver pipe isn't affected with temperature. The maxium temperature is $344.061^{\circ} \mathrm{k}$ for laminar and $310.819{ }^{\circ} \mathrm{k}$ for turbulent flow.

- Drag and skin friction coefficients decrease when Reynolds number increases. Drag coefficient is 0.07589 for laminar flow and 0.00733 for turbulent flow. Skin friction coefficient for turbulent flow is 0.01 since a rise in the rate of heat transfer typically leads to an increase in the friction factor.

- Heat transfer coefficient and Nusselt number increases with increasing of Reynolds number. The heat transfer coefficient is $6 \mathrm{~W}^{-}$ ${ }^{2} \mathrm{k}^{-1}$ for turbulent flow and $3 \mathrm{~W}^{-2} \mathrm{k}^{-1}$ for laminar flow. Nusselt number values are 1000 and 500 for turbulent and laminar flows, respectively.

- The temperature of the thermal output of the parabolic collector at the absorber tube wall increases with rising heat flux. It is increased from 350 to $390 \mathrm{~K}$ in laminar flow and from 310 to $325 \mathrm{~K}$ in turbulent flow.

- This numerical model is validated quality grid system through grid independence test of calculating Nusselt number \& velocity outlet and quality elements of orthogonlity, skewness and mesh quality. Also, Accuracy model is estimated through $\mathrm{Y}^{+}$curve and it is found in accuracy limit range.

- The model is validated by comparing its results with analytical model results. The validation approves the accuracy of the CFD analysis, and illustrates the significant effect of the optical efficiency on the parabolic trough efficiency

Future prospects for PTC system will focus on how to increase the working temperature in order to improve the thermal performance of the CSP system with less heat loss. The integrated trough collector components of the Concentrated Solar Energy Unit at low cost will need to be designed for higher demand for working temperatures.

\section{NOMENCLATURE}

\begin{tabular}{|c|c|}
\hline$A$ & Projection Pipe Area \\
\hline$x$ & Distance of Developing Flow \\
\hline$k$ & Kinetic Energy \\
\hline$L$ & Length of Geometry \\
\hline$d$ & Pipe Diameter \\
\hline$r$ & Pipe Radius \\
\hline$p$ & Pressure \\
\hline$T$ & Temperature \\
\hline$u$ & Velocity at Pipe Inlet \\
\hline \multicolumn{2}{|l|}{ Greek symbols } \\
\hline$\Phi$ & Absorbed Radiant Energy Source \\
\hline$\delta$ & Boundary Layer Thickness \\
\hline$\varepsilon$ & Dissipation Rate of Velocity \\
\hline$\rho$ & Fluid Density \\
\hline$c p$ & Fluid Specific Heat \\
\hline$\mu$ & Fluid Viscosity \\
\hline$\triangle P l$ & $\begin{array}{l}\text { Pressure Drop per Unit Distance in the Flow } \\
\text { Direction }\end{array}$ \\
\hline$\lambda$ & Thermal Conductivity \\
\hline$\eta$ & Thermal Performance Factor \\
\hline \multicolumn{2}{|l|}{ Subscripts } \\
\hline$A_{a}$ & Aperture Area \\
\hline$T_{f}$ & $\begin{array}{l}\text { Bulk Temperature of the Heating Temperature } \\
\text { Fluids }\end{array}$ \\
\hline$\sigma_{\varepsilon}, \sigma_{k}, c_{\mu}, c_{1}, c_{2}$ & Constants \\
\hline$C_{d}$ & Drag Coefficient \\
\hline$F_{r}$ & Friction Factor \\
\hline$H_{f}$ & Heat Transfer Coefficient \\
\hline$N_{u}$ & Nusselt Number \\
\hline$\eta_{\text {opt }}$ & Optical Efficiency \\
\hline$G_{b}$ & Radiation of the Solar Beam \\
\hline $\operatorname{Re}$ & Reynolds Number \\
\hline$c_{p}$ & Specific Heat Coefficient at Constant Pressure \\
\hline$T_{w}$ and $q_{w}$ & $\begin{array}{l}\text { Temperature and Average Heat Flux on Receiver } \\
\text { Pipe }\end{array}$ \\
\hline
\end{tabular}

$\begin{array}{ll}\begin{array}{l}\text { Abbreviations } \\ \text { BVP }\end{array} & \text { Boundary Value Problem } \\ C L R & \text { Cavity Linear Receiver } \\ C F D & \text { Computational Fluid Dynamics } \\ C S P & \text { Concentrated Solar Power } \\ C L-C S P & \text { Cross Linear Concentrating Solar Power } \\ D N I & \text { Direct Normal Irradiation } \\ F V M & \text { Finite Volume Method } \\ H T F & \text { Heat Transfer Fluid } \\ L B M & \text { Lattice Boltzmann Method } \\ P T C & \text { Parabolic Trough Collector } \\ P T R & \text { Parabolic Trough Receiver } \\ P T S C & \text { Parabolic Trough Solar Collector } \\ R N G & \text { Re-Normalization-Group } \\ R A N S & \text { Reynolds-Averaged Navier-Stokes } \\ S W H E & \text { Spiral Wound Heat Exchanges }\end{array}$

\section{REFERENCES}

Adriana, Alina, and Patrice Estellé. 2018. "Numerical Study on CNT Nano F1 Uids Behavior in Laminar Pipe Fl Ow." Journal of Molecular Liquids 271: 281-89. https://doi.org/10.1016/j.molliq.2018.08.161.

Al-asadi, M T, H A Mohammed, A Sh Kherbeet, and A A Al-aswadi. 2017. "Numerical Study of Assisting and Opposing Mixed Convective Nano Fl Uid Fl Ows in an Inclined Circular Pipe." International Communications in Heat and Mass Transfer 85 (May): 81-91. https://doi.org/10.1016/i.icheatmasstransfer.2017.04.015. 
Ardekani, Mehdi Niazi, Léa Al, Francesco Picano, and Luca Brandt. 2018. "International Journal of Heat and Fluid Flow Numerical Study of Heat Transfer in Laminar and Turbulent Pipe Fl Ow with Fi Nite-Size Spherical Particles." International Journal of Heat and Fluid Flow 71 (March): 18999. https://doi.org/10.1016/j.ijheatfluidflow.2018.04.002.

Bhadouriya, Rambir, Amit Agrawal, and S V Prabhu. 2015. "International Journal of Thermal Sciences Experimental and Numerical Study of Fl Uid Fl Ow and Heat Transfer in an Annulus of Inner Twisted Square Duct and Outer Circular Pipe.” International Journal of Thermal Sciences 94: 96109. https://doi.org/10.1016/j.ijthermalsci.2015.02.019.

Bie, Yu, Ming Li, Fei Chen, Grzegorz Królczyk, and Zhixiong Li. 2020. "Heat Transfer Mathematical Model for a Novel Parabolic Trough Solar Collecting System with V-Shaped Cavity Absorber." Sustainable Cities and $\begin{array}{llll}\text { Society } & 52 & \text { (August } & 2019) \text { : }\end{array}$ https://doi.org/10.1016/j.scs.2019.101837.

Canonsburg, Ansys Drive. 2015. "ANSYS ICEM CFD Tutorial Manual” 15317 (January): 724-46.

Chin, Rey C, and Jimmy Philip. 2021. "International Journal of Heat and Fluid Flow Swirling Turbulent Pipe Flows : Inertial Region and Velocity Vorticity Correlations." International Journal of Heat and Fluid Flow 87 (December 2020): https://doi.org/10.1016/j.ijheatfluidflow.2020.108767.

Damiani, André, Antonio Carlos, and Marcelo Moreira. 2015. "International Journal of Heat and Fluid Flow Numerical and Experimental Study of an Axially Induced Swirling Pipe Flow" 53: 81-90. https://doi.org/10.1016/j.ijheatfluidflow.2015.02.003.

Dutta, Prasun, Sumit Kumar Saha, Nityananda Nandi, and Nairit Pal. 2016. "Engineering Science and Technology, an International Journal Numerical Study on Flow Separation in $90^{\circ}$ Pipe Bend under High Reynolds Number by k- $\varepsilon$ Modelling." Engineering Science and Technology, an International Journal 19 (2): 904-10. https://doi.org/10.1016/j.jestch.2015.12.005.

El-bakry, M Medhat, Mahmoud A Kassem, and Muhammed A Hassan. 2021. "Passive Performance Enhancement of Parabolic Trough Solar Concentrators Using Internal Radiation Heat Shields." Renewable Energy 165: 52-66. https://doi.org/10.1016/j.renene.2020.11.003.

EvangelosBellosChristosTzivanidisKimon A.Antonopoulos. 2017. “A Detailed Working Fluid Investigation for Solar Parabolic Trough Collectors." Applied Thermal Engineering 114: 374-86. https://doi.org/10.1016/j.applthermaleng.2016.11.201.

Fan, Aiwu, Junjie Deng, Jian Guo, and Wei Liu. 2011. "A Numerical Study on Thermo-Hydraulic Characteristics of Turbulent FLow in a Circular Tube Fitted with Conical Strip Inserts." Applied Thermal Engineering 31 (1415): 2819-28. https://doi.org/10.1016/j.applthermaleng.2011.05.007.

Frigaard, I, and D M Martinez. 2009. "Predicting Laminar - Turbulent Transition in Poiseuille Pipe Flow for Non-Newtonian Fluids" 64: 254-64. https://doi.org/10.1016/j.ces.2008.10.011.

Ghasemi, Seyed Ebrahim, and Ali Akbar Ranjbar. 2017. "Numerical Thermal Study on Effect of Porous Rings on Performance of Solar Parabolic Trough Collector." Applied Thermal Engineering 118: 807-16. https://doi.org/10.1016/j.applthermaleng.2017.03.021.

Guerraiche, Djemaa, Cherif Bougriou, Khelifa Guerraiche, Loreto Valenzuela, and Zied Driss. 2020. "Experimental and Numerical Study of a Solar Collector Using Phase Change Material as Heat Storage." Journal of Energy Storage 27 (July 2019): 101133. https://doi.org/10.1016/j.est.2019.101133.

I, Victor Yakhot, and Steven A Orszag I. 1986. "Renormalization Group Analysis of Turbulence . I . Basic Theory" 1 (1): 3-51.

Jae, Byoung, Myung Ho, Seung Wook, and Kyung Doo. 2019. "Two- Fl Uid Equations for Two-Phase Fl Ows in Moving Systems." Nuclear Engineering and Technology 51 (6): 1504-13. https://doi.org/10.1016/j.net.2019.04.022.

Kanda, Hidesada, and Kenshuu Shimomukai. 2009. "Numerical Study of Pressure Distribution in Entrance Pipe Flow." Journal of Complexity 25 (3): 253-67. https://doi.org/10.1016/j.jco.2009.02.003.

Khosravi, Ali, Mohammad Malekan, and Mamdouh E H Assad. 2019. "Numerical Analysis of Magnetic Fi Eld Effects on the Heat Transfer Enhancement in Ferro Fl Uids for a Parabolic Trough Solar Collector." Renewable Energy 134: 54-63. https://doi.org/10.1016/j.renene.2018.11.015.

Kou, Jie, Yi Chen, and Junqiang Wu. 2020. "Chemical Engineering \& Processing: Process Intensi Fi Cation Numerical Study and Optimization of Liquid-Liquid Fl Ow in Cyclone Pipe." Chemical Engineering \& Processing: Process Intensification 147 (October 2019): 107725. https://doi.org/10.1016/j.cep.2019.107725.

Launder, Brian. 2017. "The Numerical Computation of Turbulent Flow Computer Methods" 7825 (March 1974). https://doi.org/10.1016/00457825(74)90029-2.

Li, Lin, Ping Lin, Xinhui Si, and Liancun Zheng. 2017. "Journal of Computational and Applied A Numerical Study for Multiple Solutions of a Singular Boundary Value Problem Arising from Laminar Flow in a Porous Pipe with Moving Wall." Journal of Computational and Applied Mathematics 313: 536-49. https://doi.org/10.1016/j.cam.2016.10.002.

Li, Shulei, Weihua Cai, Jie Chen, Haochun Zhang, and Yiqiang Jiang. 2018a. "International Journal of Heat and Mass Transfer Numerical Study on Condensation Heat Transfer and Pressure Drop Characteristics of Ethane / Propane Mixture Upward Flow in a Spiral Pipe." International Journal of Heat and Mass Transfer 121: 170-86. https://doi.org/10.1016/j.ijheatmasstransfer.2017.12.140.

—. 2018b. "International Journal of Heat and Mass Transfer Numerical Study on the Flow and Heat Transfer Characteristics of Forced Convective Condensation with Propane in a Spiral Pipe." International Journal of Heat and Mass Transfer 117: 1169-87. https://doi.org/10.1016/j.ijheatmasstransfer.2017.10.080.

Liu, Hongtao, Rongrong Zhai, Kumar Patchigolla, Peter Turner, and Yongping Yang. 2021. "Off-Design Thermodynamic Performances of a Combined Solar Tower and Parabolic Trough Aided Coal-Fired Power Plant." Applied Thermal Engineering 183 (P1): 116199. https://doi.org/10.1016/j.applthermaleng.2020.116199.

Liu, Lang, Zhiyu Fang, Chongchong Qi, Bo Zhang, Lijie Guo, and K I L Song. 2019. "Numerical Study on the Pipe Fl Ow Characteristics of the Cemented Paste Back Fi L1 Slurry Considering Hydration Effects." Powder Technology 343: 454-64. https://doi.org/10.1016/j.powtec.2018.11.070.

Liu, Peng, Zhimin Dong, Jinyi Lv, Feng Shan, Zhichun Liu, and Wei Liu. 2020. "Numerical Study on Thermal-Hydraulic Performance and Exergy Analysis of Laminar Oil Flow in a Circular Tube with Fluid Exchanger Inserts." International Journal of Thermal Sciences 153. https://doi.org/10.1016/j.ijthermalsci.2020.106365.

Liu, Peng, Zhimin Dong, Hui Xiao, Zhichun Liu, and Wei Liu. 2021. 
"Thermal-Hydraulic Performance Analysis of a Novel Parabolic Trough Receiver with Double Tube for Solar Cascade Heat Collection." Energy 219: 119566. https://doi.org/10.1016/j.energy.2020.119566.

Madadi, Vahid, Amir Rahimi, and Mohammad Divband. 2020. "Coupled Optical and Thermal Analyses of a New Type of Solar Water Heaters Using Parabolic Trough Re Fl Ectors." Sustainable Energy Technologies and $\begin{array}{llll}\text { Assessments } \quad 40 & \text { (December } 2019): & 100780 .\end{array}$ https://doi.org/10.1016/j.seta.2020.100780.

Malviya, Rajkumar, Ayush Agrawal, and Prashant V Baredar. 2020. "Materials Today: Proceedings A Comprehensive Review of Different Heat Transfer Working Fluids for Solar Thermal Parabolic Trough Concentrator." Materials Today: Proceedings, no. xxxx. https://doi.org/10.1016/j.matpr.2020.09.240.

Mishra, Prashant, Mukesh Pandey, Yutaka Tamaura, and Sumit Tiwari. 2021. "Numerical Analysis of Cavity Receiver with Parallel Tubes for Cross- Linear Concentrated Solar System." Energy 220: 119609. https://doi.org/10.1016/j.energy.2020.119609.

N.DKaushika. 1993. "Viability Aspects of Paraboloidal Dish Solar Collector Systems.” Renewable Energy 3 (6-7): 787-93. Viability aspects of paraboloidal dish solar\%0Acollector systems.

Ohira, Katsuhide, Atsuhito Ota, Yasuaki Mukai, and Takumi Hosono. 2012. "Numerical Study of Flow and Heat-Transfer Characteristics of Cryogenic Slush Fluid in a Horizontal Circular Pipe ( SLUSH-3D ) Q." $\begin{array}{llll}\text { Cryogenics } & 52 & \text { (7-9): }\end{array}$ https://doi.org/10.1016/j.cryogenics.2012.04.006.

Onokoko, Charles Landa, Nicolas Galanis, Sébastien Poncet, and Michel Poirier. 2019. "International Journal of Thermal Sciences Heat Transfer of Ice Slurry Fl Ows in a Horizontal Pipe: A Numerical Study" 142 (November 2018):

https://doi.org/10.1016/j.ijthermalsci.2019.04.004.

"Parabolic Trough Reflector." n.d. Alternative Energy Tutorials. http://www.alternative-energy-tutorials.com/solar-hot-water/parabolictrough-reflector.html.

Patro, Pandaba, Ravi Gupta, and Aswini Kumar. 2015. "Numerical Study for the Prediction of Heat Transfer in a Pulsating Turbulent Flow in a Pipe." Procedia Engineering 127: https://doi.org/10.1016/i.proeng.2015.11.422.

Peng, Cheng, Nicholas Geneva, Zhaoli Guo, and Lian-ping Wang. 2018. "Direct Numerical Simulation of Turbulent Pipe Flow Using the Lattice Boltzmann Method." Journal of Computational Physics 357: 16-42. https://doi.org/10.1016/j.jcp.2017.11.040.

Pina, A, P Ferrão, J Fournier, B Lacarrière, and O Le Corre. 2017. "ScienceDirect ScienceDirect ScienceDirect The 15th International Symposium on District Heating and Cooling Receiver with Concentric and Eccentric Pipe Inserts Assessing the Feasibility of Using the Heat DemandOutdoor Temperature Function for a Long-Term ." Energy Procedia 142: 624-29. https://doi.org/10.1016/i.egypro.2017.12.103.
Polo, Marco A, Sergio Quezada, S Heriberto, and I C Ricardo. 2019. "Case Studies in Thermal Engineering Modeling and Simulation to Determine the Thermal Efficiency of a Parabolic Solar Trough Collector System" 16 (August). https://doi.org/10.1016/j.csite.2019.100523.

Reddy, K S, G Veershetty, and T Srihari Vikram. 2016. "ScienceDirect Effect of Wind Speed and Direction on Convective Heat Losses from Solar Parabolic Dish Modified Cavity Receiver." Solar Energy 131: 183-98. https://doi.org/10.1016/j.solener.2016.02.039.

Shpilrain, E.E. 2011. "AIR (PROPERTIES OF)." 10.1615/AtoZ.a.air_properties_of.

Shuang-YingWu, LanXiao, YidingCao, and You-RongLi. 2010. "Convection Heat Loss from Cavity Receiver in Parabolic Dish Solar Thermal Power System: A Review." Solar Energy 84 (8): 1342-55. https://doi.org/10.1016/j.solener.2010.04.008.

Tu, Wenbin, Yun Wang, and Yong Tang. 2016. "A Numerical Study on Thermal-Hydraulic Characteristics of Turbulent Flow through a Circular Tube Fitted with Pipe Inserts.” Applied Thermal Engineering 101: 413-21. https://doi.org/10.1016/j.applthermaleng.2016.01.106.

XueChen, Xin-linXia, Xian-hongDong, and Gui-longDai. 20152. "Integrated Analysis on the Volumetric Absorption Characteristics and Optical Performance for a Porous Media Receiver.” Energy Conversion and Management 105 (15): 562-69

https://doi.org/10.1016/j.enconman.2015.08.028.

Yang, Lin, Xiang Ling, Hao Peng, Luanfang Duan, and Xiaoyi Chen. 2019. "Starting Characteristics of a Novel High Temperature Fl at Heat Pipe Receiver in Solar Power Tower Plant Based of "Flat-Front' Startup Model.” Energy 183: 936-45. https://doi.org/10.1016/j.energy.2019.07.007.

Yang, Liu, and Kai Du. 2020. "Thermo-Economic Analysis of a Novel Parabolic Trough Solar Collector Equipped with Preheating System and Canopy." $\quad$ Energy 211: 118900. https://doi.org/10.1016/j.energy.2020.118900.

Zayed, Mohamed E, Jun Zhao, Ammar H Elsheikh, Zhennan Zhao, Shengyuan Zhong, and A E Kabeel. 2021. "Comprehensive Parametric Analysis, Design and Performance Assessment of a Solar Dish / Stirling System." Process Safety and Environmental Protection 146: 276-91. https://doi.org/10.1016/j.psep.2020.09.007.

Zhang, Yanping, Hu Xiao, Chongzhe Zou, Quentin Falcoz, and Pierre Neveu. 2020. "Combined Optics and Heat Transfer Numerical Model of a Solar Conical Receiver with Built-in Helical Pipe.” Energy 193: 116775. https://doi.org/10.1016/j.energy.2019.116775.

Zheng, Xuejing, Rui Shi, Yaran Wang, Shijun You, Huan Zhang, Junbao Xia, and Shen Wei. 2019. "Mathematical Modeling and Performance Analysis of an Integrated Solar Heating and Cooling System Driven by Parabolic Trough Collector and Double-Effect Absorption Chiller." Energy and Buildings 202: 109400. https://doi.org/10.1016/j.enbuild.2019.109400. 